\title{
Protection Automatics of Medium Voltage Networks-Characteristics of Earth Fault Detection Criteria
}

\author{
Bernard Wiecha ${ }^{1, *}$, Michał Wiecha ${ }^{1}$, Aleksandra Wiecha ${ }^{2}$ \\ ${ }^{1}$ Department of Electrical Power Engineering, Wroclaw University of Science and Technology, Poland. \\ ${ }^{2}$ Department of Electrical Power Engineering, RWTH AACHEN University, Germany.
}

How to cite this paper: Bernard Wiecha, Michał Wiecha, Aleksandra Wiecha. (2021) Protection Automatics of Medium Voltage Networks-Characteristics of Earth Fault Detection Criteria. Journal of Electrical Power \& Energy Systems, 5(1), 58-70.

DOI: 10.26855/jepes.2021.05.003

Received: April 6, 2021

Accepted: April 30, 2021

Published: May 24, 2021

*Corresponding author: Bernard Wiecha, Department of Electrical Power Engineering, Wroclaw University of Science and Technology, Poland.

Email: bernard.wiecha@pwr.edu.pl

\begin{abstract}
Designing algorithms for power protection automation is characterized by a large number of ideological concepts and methods of implementation based on analog measurement signals. Originally, digital solutions replicated concepts previously known from electromechanical protection. Depending on the electrical correctness of the analog signal parameters, the operation of the protection devices was affected by errors directly proportional to the errors of the signal sources. Technical progress also resulted in the development of measuring technology. Equipping protection relays with analog-to-digital converters improved the quality of detection, but did not change the operating philosophy of the algorithms. They used standard protection criteria based on the fundamental components of the protection signals, referring to the positive sequence zero sequence of current and voltage. The article presents problems resulting from the use of measuring devices and zero sequence current and voltage filters. The characteristics of conventional and unconventional criteria, based on multi-frequency analyzes of short-circuit signals, and the analysis of the effectiveness of algorithms based on positive sequence zero sequence of current and voltage in comparison to algorithms based on multi-frequency short-circuit signal analyzes were also performed.
\end{abstract}

\section{Keywords}

Protection Criteria, Admittance Multi-Frequency, Erath Fault Detection Intermittent Earth Fault, Digital Earth-Fault Protection

\section{Preface}

Earth faults (earth faults) in MV networks constitute the vast majority of the total number of faults and often develop into polyphase faults, often becoming the cause of avalanche disturbances. Moreover, the flow of earth fault currents poses a significant threat to living creatures present in the vicinity of the fault location. Due to the above, it is necessary to use earth-fault protection in these networks in order to locate the earthed line and eliminate the disturbance.

Determining a universal criterion for earth faults in MV networks to be implemented in a configuration of digital earth-fault protection that would be effective and would work properly in each network is a very complicated 
process and requires a number of input data for analysis.

The reason for this is the characteristic features of the ground fault current, the module and argument of which depend on the method of earthing the neutral point of the supply transformer and the nature of the connected network, i.e. overhead-cable, cable or overhead.

Therefore, in order to select an appropriate protection criterion (configuration of digital earth-fault protection), each network should be analyzed and considered individually

\section{Measurements of the magnitudes of supplying earth-fault protection}

\subsection{Introduction}

As a result of earth faults, additional zero-sequence currents and voltage sequences appear in MV networks. The primary values of these quantities measured in the pre-short circuit condition result from the asymmetry of the MV network itself and the measurement errors of symmetrical components filters. The basic measurement quantities (the so-called supply) of the earth-fault protection are:

- $\quad$ zero sequence voltage measured on the busbars of MV substations;

- $\quad$ zero sequence current measured at the point where the line exits the MV substation.

The value of the zero sequence of the signal is obtained by summing the phase values of this signal, therefore the measurement transformers installed in all phases are used to implement the zero sequence filter. Remember to properly connect the secondary windings of the measuring transformers.

\subsection{Filtr zero sequence voltage [1]}

In the case of a zero sequence voltage filter, the secondary windings of the voltage transformers must be connected in series. This connection, called an open triangle, is shown in Figure 1.

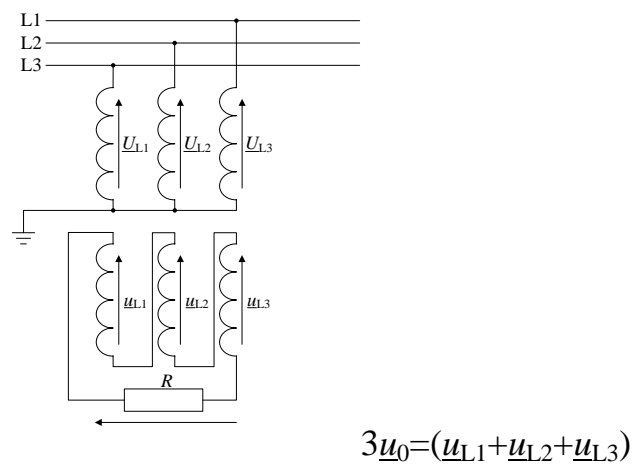

Figure 1. Installation diagram of a core balance transformer Connection of voltage transformers.

Voltage transformers, which are special single-phase transformers, usually have two secondary windings. Transformers connected between two phases have a ratio value of UpN/100, where UpN is the rated RMS primary voltage in volts [8]. The ratio of phase-to-earth transformers with windings for measuring both phase and zero sequence voltages is

$$
\left(U_{p N} / \sqrt{3}\right) /(100 / \sqrt{3}) /(100 / 3) .
$$

Therefore, on the secondary side of the zero sequence filter, the voltage at a metallic short circuit should theoretically be $100 \mathrm{~V}$.

In practice, when selecting the settings of all earth-fault protection, errors caused by the zero sequence voltage filters are not directly taken into account. The influence of these errors is indirectly taken into account, along with other phenomena disturbing the measurement of criterion quantities, by introducing a safety factor $k_{b}$.

\subsection{Filtry zero sequence current [1]}

In practice, two methods of measuring the zero sequence current are used: parallel connection of phase current 
transformers in the so-called Holmgreen system or the use of the so-called Ferranti transformer, which is an earth fault transformer in the form of a magnetic core with a wound secondary winding. In the case of a transformer, Ferranti winding primary is a three-phase power cable, and the measurement of the zero sequence is performed by summing up the magnetic fields induced by currents in three phase conductors led through the transformer window. A very important issue from the point of view of the usability of the measured current quantities that power the earth-fault protections are measurement errors caused by the above-mentioned, both methods.

In the earth-fault protection, which use the Holmgreen circuit as a zero sequence filter, there is a problem with obtaining the appropriate sensitivity. The use of this measurement method is associated with errors resulting from unequal magnetization characteristics of the transformers, which are components of the system, and the possible saturation of the magnetic circuit [3].

The core balance current transformer (zero sequence current transformer) is characterized by much better properties, the installation diagram of which is presented in Figure 2 [1].

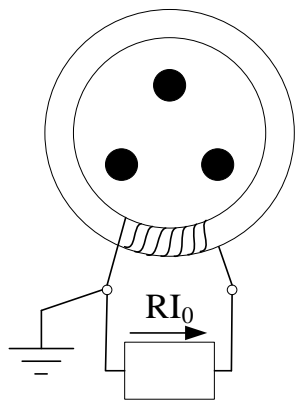

Figure 2. Installation diagram of the Ferranti transformer.

These transformers are built in various versions, adapted to be installed on a cable, a group of cables or a generator busbar. In operating conditions, the primary winding is a three-phase power cable. The secondary main winding is wound evenly over the entire length of the core. The transformer is installed at the end of the cable below the head, which must be insulated from the earthed supporting structure, and the head earthing conductor must be led through the transformer's core window. Thanks to this procedure, only the sum of the currents flowing only in the cable conductors is measured. As a result, a current flows through the load of the transformer corresponding to three times the value of the zero sequence current in the cable:

$$
3 \underline{I}_{\mathrm{Op}}=\underline{I}_{\mathrm{L} 1}+\underline{I}_{\mathrm{L} 2}+\underline{I}_{\mathrm{L} 3}
$$

However, this design does not guarantee zero current errors of this zero sequence current filter. The cause of these errors is unequal mutual inductance between the individual primary circuits and the main winding.

Assuming sinusoidal currents, $I_{a}, I_{b}, I_{c}, I_{p k}$ the fault voltage induced in the secondary winding is determined by the following relationship:

$$
\underline{E}_{\mathrm{u}}=\underline{I}_{\mathrm{a}} \underline{Z}_{\mathrm{aM}}+\underline{I}_{\mathrm{b}} \underline{Z}_{\mathrm{bM}}+\underline{I}_{c} \underline{Z}_{\mathrm{cM}}+\underline{I}_{\mathrm{pk}}\left(\underline{Z}_{\mathrm{pM}}-\underline{Z}_{\mathrm{zM}}\right)
$$

where:

$Z_{a M}, Z_{b M}, Z_{c M^{-}}$mutual impedances between the phase conductors of the cable and the winding of the transformer, $Z_{p M^{-}}$mutual impedance between the cable sheath and the secondary winding,

$Z_{z M}$ - mutual impedance between the grounding conductor and the secondary winding,

$I_{p k}$ - current in the cable sheath.

The basic condition for the reduction of the value of the fault current is the symmetrical assembly of the phase conductors or the cable in the window of the core transformer. Then the dependence simplifies to form [3] [5]:

$$
\underline{E}_{\mathrm{u}}=\underline{I}_{\mathrm{pk}}\left(\underline{Z}_{\mathrm{pM}}+\underline{Z}_{\mathrm{zM}}\right)
$$

Due to the fact that the impedances $Z_{n M}$ and $Z_{Z M}$ have generally different values, at high stray currents $I_{p k}$ there is a fault current, which in some cases may cause a malfunction of the protection [In order to reduce the error errors as much as possible, in theory to zero, a structural symmetrization of the core system, phase conductors and the grounding conductor is required. The lack of axial symmetry for the concentric location of the phase conductors 
with respect to the transformer window at the moment of the flow of maximum line currents (short-circuit load) may result in local core saturations, which in turn leads to transformation errors. Another source of potential transformation errors is the change in the direction of the conductor (cable) exit just outside the transformer window. An in-depth analysis of transformation errors resulting from the assembly asymmetry of the cable-Ferranti transformer system is described in [2] [5].

Due to the complexity of the problem of transformation errors in real systems consisting of three wires passed through the transformer window, it has been widely accepted that the errors for the Holmgreen system and the Ferranti transformer is constant and do not depend on the measured zero sequence. The proposed values of errors on the secondary side of the above-mentioned zero sequence filters are as follows: $30 \mathrm{~mA}$ (for the Holmgreen system) and $10 \mathrm{~mA}$ (for the Ferranti transformer) [3].

\section{Conventional ground fault criteria}

\subsection{Zero-voltage criterion Uo>}

The zero-voltage criterion is used in the autonomous zero-voltage protection, in the form of a start-up criterion in admittance and admittance protection, and as a start-up criterion of the AWSCz system. Its primary task is to detect a short-circuit condition in the MV network and as such it has a decisive influence on the range of detected pass resistance through admittance protections.

A very important factor in relation to the sensitivity of admittance protection, and not only, is the selection of this criterion settings for various methods of grounding the neutral point of the network. First of all, the settings must be selected so that there are no unnecessary starts in the states of natural to-ground asymmetry of the network. It should be mentioned that in modern MV networks with a large share of cable lines, the natural unbalance voltages are relatively small (in the order of $0.5 \%$ of the phase voltage of the MV network). In networks with the neutral grounded by a resistor, the value of the zero sequence is correspondingly reduced compared to the same network without a grounding resistor.

Attention should also be paid to the relatively large suggested settings for the zero-voltage criterion of the starting elements of the admittance protections. The following settings are usually proposed in the literature:

$10-20 \mathrm{~V}$ for networks with an insulated neutral point,

5-10 V for networks with the neutral point grounded by a resistor, while in "symmetrical" overhead networks running on the ground with high resistivity even $3 \mathrm{~V}$,

15-25 V for compensated networks. Often it is also possible to set $10 \mathrm{~V}$ [3] [8].

The justification for this is the fact that with the increase in the transition restance and the decrease in the value of the zero sequence voltage and current, the share of components not originating from short-circuit phenomena in the above-mentioned signals supplying admittance, conductance or susceptance protection is increasing. Taking into account also the complex nature of these disturbing signals (no possibility to define the disturbance argument), the protection should be properly unset against short-circuit cases, in which their participation will lead to significant errors in calculating the value calculation of the criteria.

The main disturbing quantities are the network unbalance voltage and the errors of the zero sequence current filters in the expression that describes the measured admittance:

$$
\underline{Y}_{0 \mathrm{p}}=-\frac{3 \underline{I}_{0 \mathrm{p}}}{3 \underline{U}_{0 \mathrm{p}}} \stackrel{\mu}{=}-\frac{\underline{I}_{\mathrm{i} 0}+\underline{I}_{0}}{\underline{U}_{0 \mathrm{z}}+\underline{U}_{0 \mathrm{asc}}}
$$

where:

$$
\begin{aligned}
& \underline{U}_{0 \mathrm{z}}=\frac{\underline{E}_{\mathrm{L}}}{1+R_{\mathrm{F}} \omega C_{0 \mathrm{~S}}\left(d_{0}-\mathrm{js}\right)} \\
& \underline{U}_{0 \mathrm{asc}}=\frac{R_{\mathrm{F}} \mathrm{j} \omega C_{0 \mathrm{~S}} \underline{U}_{\mathrm{asc}}}{1+R_{\mathrm{F}} \omega C_{0 \mathrm{~S}}\left(d_{0}-\mathrm{js}\right)} \\
& d_{0}=\frac{G_{\mathrm{N}}+G_{0 S}}{\omega C_{0 \mathrm{~S}}}
\end{aligned}
$$


where on the healthy line the zero component of the current is equal to:

$$
\underline{I}_{0 \mathrm{i}}=\frac{-\underline{E}_{\mathrm{L}} \mathrm{j} \omega C_{0 \mathrm{i}}}{1-R_{\mathrm{F}} \mathrm{j} \omega C_{0 \mathrm{~S}} s}
$$

while on the grounded line:

$$
\underline{I}_{0 \mathrm{i}}=\frac{-\underline{E}_{\mathrm{L}} \mathrm{j} \omega C_{0 \mathrm{~S}}\left(s+\frac{C_{0 \mathrm{i}}}{C_{0 \mathrm{~S}}}\right)}{1-R_{\mathrm{F}} \mathrm{j} \omega C_{0 \mathrm{~S}} s}
$$

$\underline{I}_{0 \text { ip }} \quad-\quad$ zero sequence current measured on the i-th line,

$\underline{I}_{0 \mathrm{i}} \quad-\quad$ zero sequence current of the i-th line (to earth or without short circuit),

$\underline{I}_{0 \mu} \quad-\quad$ current error of the zero sequence current filter converted to the primary side; a constant value for the secondary side of 10-20 mA for a Ferranti transformer or $3050 \mathrm{~mA}$ for a Holgreen system is assumed,

$\underline{U}_{0 \mathrm{p}} \quad-\quad$ zero sequence voltage measured on switchgear busbars,

$\underline{U}_{0 z} \quad-\quad$ zero sequence voltage component resulting directly from the occurrence of an earth fault through the short-circuit resistance $R_{\mathrm{F}}$,

$\underline{U}_{0 \text { asc }} \quad-\quad$ zero sequence voltage component resulting directly from the network capacitive unbalance and the occurrence of an earth fault through the transition resistance $R_{\mathrm{F}}$,

$\underline{U}_{\text {asc }} \quad-\quad$ zero sequence voltage component resulting directly from the network capacitive unbalance in the pre-short circuit condition in the network with an isolated neutral point,

$d_{0} \quad-\quad$ network attenuation factor,

$G_{0 \mathrm{~S}} \quad-\quad$ earth conductance of the entire MV network,

$G_{\mathrm{N}} \quad-\quad$ conductance of the neutral point earthing element.

\subsection{Zero-current criterion Io>}

The Io> zero-current criterion is a one-size criterion used to protect line fields in networks with an insulated neutral point and in networks with a resistor earthed neutral. It does not fulfill its functions in compensated networks due to too low sensitivity. With regard to networks with an insulated neutral point, it can only be used for relatively short lines for which the earth-leakage capacitive current does not exceed $40 \%$ of the total network capacitive earth-leakage current. When using the admittance criterion or from the admittance group, the Io $>$ criterion should be treated as a backup criterion, e.g. in the case of a failure of the Uo measuring circuits.

\subsection{Directional power of active and passive criteria [3], [5], [6]}

The active and passive criteria are bivalent criteria, although the absolute value of the Uo signal is not used to calculate the criterion value, but only the angle between the zero sequence vectors of the voltage and current of the protected line. Hence, this criterion is not a purely power criterion and could be referred to as the angular (angular-dependent) zero-current criterion. It acts as overcurrent with respect to the angle-dependent starting threshold:

$$
I_{0 \mathrm{p}}>\frac{I_{0 \mathrm{r}}}{\cos \left(\varphi-\varphi_{\mathrm{ch}}\right)}
$$

where:

$\underline{I}_{0 \mathrm{r}} \quad-\quad$ current setting value (maximum current sensitivity value),

$\varphi \quad-\quad$ calculated angle of phase shift between $\underline{U}_{0 \mathrm{p}} \underline{\mathrm{i}} \underline{\mathrm{I}}_{0 \mathrm{p}}$,

$\varphi_{\text {ch }} \quad-\quad$ angle of highest current sensitivity $\left(0^{\circ}\right.$ for the power of attorney criterion i $90^{\circ}$ for passive).

Power protection can be used in AWSCz-compensated line bays, in networks with the neutral point grounded by a resistor and grounded by a parallel reactor-resistor system. These protections are not suitable for use in compensated networks without AWSCz. Passive protection is recommended for networks with an isolated neutral point.

\subsection{Kryterium admitancyjne $Y_{0}>[$}

The admittance criterion Yo> operates on the basis of the modulus of the measured admittance of the protected line, and the criterion quantity is defined by the expression: 


$$
Y_{0 \mathrm{p}}=-\frac{3 I_{0 \mathrm{p}}}{3 U_{0 \mathrm{p}}}
$$

An issue frequently raised is the independence of this criterion quantity from the transition resistance, which is the case only when the network is perfectly symmetrical. This discrepancy is significant only when the transition resistance is high, and the limited dependence of this criterion on the transition resistance is a great advantage, which gives it a significant advantage over the protections listed in the previous sections. For metallic faults, the network asymmetry does not affect the value of the zero sequence current in the lines with the fault.

Neglecting in formula 3.1. The zero sequence error and individual earth conductances of individual lines can be expressed as the approximate value of the measured admittance for a grounded line:

$$
\underline{Y}_{0 \mathrm{i}}=\omega C_{0 \mathrm{~S}}\left[d_{0}-\mathrm{j}\left(s-\frac{C_{0 \mathrm{i}}}{\mathrm{C}_{0 \mathrm{~S}}}\right)\right]
$$

while for a healthy line in an earthed network:

$$
\underline{Y}_{0 \mathrm{i}}=-\mathrm{j} \omega C_{0 \mathrm{i}}
$$

This protection is launched under the fulfillment of two conditions:

$$
Y_{0 \mathrm{i}} \geq Y_{0 \mathrm{ir}} \quad \mathrm{i} \quad U_{0} \geq U_{0 \mathrm{r}}
$$

where $Y_{0 i}$ is the radius of the circular start-up characteristic selected individually for each line. The value of $Y_{0 i}$ depends, inter alia, on the residual capacitive current of the protected line and the adopted admittance measurement error determined by the relationship:

$$
\Delta Y_{0 \mu}=\frac{\Delta I_{0 \mu}}{U_{0 r}}
$$

which makes it necessary to select a setting:

$$
Y_{0 \mathrm{ir}} \gg \frac{k_{\mathrm{b}} I_{\mathrm{CL} i}}{U_{0 \max } \vartheta_{i 0}}+\Delta Y_{0}
$$

The safety factor. $k_{b}$ should be greater than 1.2

The admittance criterion has the best conditions for operation in networks with a resistor earthed neutral point. Under certain conditions, it is possible to use this criterion in networks with an insulated neutral point and in AWSCz compensated networks [3] [5].

\subsection{Conductance criterion}

In networks permanently earthed through a resistor or equipped with AWSCz systems during an earth fault, the conductance of the earth line increases. This phenomenon makes it possible to use the active admittance component, calculated on the basis of supply signals $3 \underline{U_{0}}$ and $3 \underline{\text { Io }}$, for earth fault detection in the mentioned MV networks.

The detection of the ground fault of the i-th line takes place on the basis of meeting two conditions:

$$
G_{0 \mathrm{i}} \geq G_{0 \mathrm{ir}} \quad \text { i } \quad U_{0} \geq U_{0 \mathrm{r}}
$$

where:

$G_{0 \mathrm{i}}=\operatorname{Re}\left(\underline{Y}_{0 \mathrm{i}}\right)=\operatorname{Re}\left(G_{0 \mathrm{i}}+j B_{0 \mathrm{i}}\right)$ is the zero sequence conductance measured in the line circuits, $G_{0 \mathrm{ir}}$ is the setting value of the conductive earth-fault criterion.

The settings of the conductance protection are selected on the basis of the current errors of the zero sequence current filters according to the following dependence:

$$
G_{0 \mathrm{r} \mathrm{mb}} k_{\mathrm{b}} \Delta Y_{0}=k \frac{\Delta I_{0 \mu}}{U_{0 \mathrm{r}}}
$$

where the value of the safety factor $k_{b}$ should be approximately 1.2 in compensated networks, and 2.0 for networks with the neutral point earthed by a resistor. As you can see, the setting value does not depend on the parameters of 
the protected line, nor on the value imposed by the earthing resistor of the active current. This is due to the fact that in the criterion the reactive current is not taken into account, and the fact that in the "healthy" line (not covered by the short-circuit), the zero sequence is only reactive (disregarding the earth conductance of the line). The active component appears only in the residual current of the grounded line.

\subsection{Susceptance directional criterion $B_{0 k}>$}

The application of the susceptance criterion, and only in the directional version G0k>, is limited only to a network with an insulated neutral point or it can possibly be used in a network earthed through a resistor, in which the auxiliary transformer is turned off.

Detection of a ground fault in the i-th line is based on the fulfillment of two conditions:

$$
B_{0 \mathrm{i}} \geq B_{0 \mathrm{ir}} \quad \text { i } \quad U_{0} \geq U_{0 \mathrm{r}}
$$

where:

$B_{0 \mathrm{i}}=\operatorname{Im}\left(\underline{Y}_{0 \mathrm{i}}\right)=\operatorname{Im}\left(G_{0 \mathrm{i}}+\mathrm{j} B_{0 \mathrm{i}}\right)$ is the zero sequence susceptance measured in line circuits, $B_{0 i r}$ the setting value of the susceptance earth-fault protection criterion.

The settings of the susceptance protections are selected on the basis of current errors of the zero sequence current filters according to the following relationship:

$$
B_{0 \mathrm{r}}>\mathrm{k} k_{\mathrm{b}} \Delta Y_{0}=k \frac{\Delta I_{0 \mu}}{U_{0 \mathrm{r}}}
$$

where the safety factor $k_{b}$ should have values within 1.2-2.0.

\section{Unconventional ground fault criteria}

\subsection{Application of the Hilbert transform [2], [8], [9]}

An important criterion for detecting faults in distribution lines is the directional criterion. Therefore, it is often proposed to use the information about the reactive power flow direction to determine the fault location in the MV network. This method is based on the analysis of the fundamental component of protection signals, however, it is unreliable in the case of intermittent faults. Therefore, it is proposed to use information about reactive power in the entire frequency spectrum of the observed signals [7].

In order to adapt the above-mentioned power direction for non-sinusoidal transient cases, the appropriate instantaneous power should be determined, which should meet the following criteria:

- $\quad$ for any harmonic, the integral of the instantaneous reactive power in one period of this component gives reactive energy; the sign of reactive energy is positive from the source side when the load is inductive or negative for a capacitive load, or induction is a receiver of reactive (positive) power, and capacity is a generator of reactive (positive) power,

- conventional reactive power of fundamental component should be a special case according to the definition of instantaneous reactive power.

The convention described in [7] proposes to calculate the reactive power of the selected spectrum of the protection signal in a manner generally accepted for the calculation of active power as the average value of the instantaneous power after the period of the appropriate harmonic according to the Budeanu reactive power theory:

$$
P(t)=\frac{1}{T} \int_{t-T}^{t} u_{0}(\tau) i_{0}(\tau) \mathrm{d} \tau
$$

Expression 4.1. Enables the determination of the active power of a periodic signal in its full spectrum. However, its use to determine reactive power requires a phase shift of all voltage or current signal components by 90 without changing the amplitude of the spectrum. Such an operation is possible thanks to the Hilbert transform, which in the continuous version is defined by the following formula:

$$
\operatorname{HT}[x(t)]=\int_{-\infty}^{+\infty} h(t-\tau) x(\tau) \mathrm{d} \tau
$$


where $h(t)$ is the weight function of the Hilbert transform of the following formula:

$$
h(t)=\frac{1}{\pi t} \quad-\infty<t<+\infty
$$

where:

$$
h(n)= \begin{cases}0, & \text { for } n-\text { even } \\ \frac{2}{n \pi}, & \text { for } n-\text { uneven }\end{cases}
$$

In networks with an isolated or grounded neutral point, the individual network components maintain their character for individual harmonics, i.e. their arguments remain constant, while the capacitive susceptance modules increase, while the inductive modules decrease in proportion to the harmonic order. Conductances are constant for all components of the considered spectrum. Therefore, the reactive power direction of the individual frequency components is the same. Therefore, the instantaneous reactive power can be calculated from the equation 4.1 after the prior Hilbert transform of the signal $u_{0}(t)\left(\right.$ or $\left.i_{0}(t)\right)$ according to the following formula:

$$
Q(t)=\frac{1}{T} \int_{t-T}^{t} \operatorname{HT}\left[u_{0}(\tau)\right] i_{0}(\tau) \mathrm{d} \tau
$$

Several characteristic features of $Q(t$ calculated according to (4.5) should be mentioned, which make it predestined to determine the direction of intermittent faults. First of all, in the calculation of $Q(t$, the powers of all components of protection signals are used, which is essential in the case of repeated transients of the short-circuit process. Moreover, this value is a generalization of the passive approach to determining the fault direction. Also included is a fundamental component which is still used in the case of metallic earth faults. The integrating-averaging character of the calculation formula (4.5) additionally makes the method more resistant to interference in the form of protection signal noise.

\subsection{Multi-frequency admittance criterion [2], [8], [9]}

The operation of the multi-frequency admittance criterion is based on the multi-frequency admittance measurement in combination with the phase summation technique. A wide frequency spectrum of the measured supply signals $\left(u_{0}, i_{0}\right)$ is used here. In addition to the fundamental frequency, the harmonic components of the protection signals are used in the form of appropriate admittances, added in a complex form to the earth admittance determined for the fundamental component. Thus, an admittance fault direction indicator is obtained:

$$
\underline{Y}_{\text {osum }}=\operatorname{Re}\left[\underline{Y}_{0}^{1}\right]+\mathrm{j} \cdot \operatorname{Im}\left[\underline{Y}_{0}^{1}+\sum_{n=2}^{m} \underline{Y}_{0}^{n}\right]
$$

where:

$\underline{Y_{0}^{1}}=\underline{I_{0}^{1}} /-\underline{U_{0}^{1}}$ is the admittance to earth determined for the fundamental component,

$\overline{Y_{0}^{n}}=\overline{I_{0}^{n}} /-\overline{U_{0}^{n}}$ is the admittance for the nth harmonic.

The determined susceptances for the appropriate harmonics have opposite signs in the healthy lines and with earth fault lines, analogically to the fundamental component, and they increase proportionally with the order of the harmonic.

In order to ensure the credibility of the earth fault direction assessment, also during intermittent faults, the admittances calculated on the basis of (4.6) are summed up in a complex in the selected integration window:

$$
\underline{Y}_{\text {osum_CPS }}=\sum_{i=t_{\text {sart }}}^{t_{\text {end }}} \operatorname{Re}\left[\underline{Y}_{\text {sum }}(i)\right]+\mathrm{j} \cdot \sum_{i=t_{\text {start }}}^{t_{\text {end }}} \operatorname{Im}\left[\underline{Y}_{\text {sum }}(i)\right] j
$$

This approach is more general than the admittance criterion or the admittance security group using only the base member. However, computing the admittance for harmonics requires individual bandpass filters for orthogonalization of protection signals.

This algorithm ensures good sensitivity and stability even in the case of the most demanding earth faults with highly distorted power signals, such as, for example, during interrupted earth faults. It also provides a universal, end-to-end protection function that selectively detects all types of earth faults. 


\section{Comparative analysis of the multi-frequency criterion with conventional admittance criteria [2], [8], [9]}

\subsection{Introduction}

The comparative analysis was carried out in the ATPDrow environment, in which the operating conditions of the MV network during an earth fault were mapped for the selected multi-frequency criteria developed for three methods of grounding the neutral point of the MV distribution network. The models of the short-circuit arc and the dynamic changes of the errors of the zero sequence current filters have been implemented in a way that most faithfully reflects the real disturbances of the short-circuit signal by the harmonic source in the spectrum from the 1 st to the 16th harmonic. For the mentioned methods of earthing, the recommended conventional protection criteria, i.e..:

- susceptance criterion for an isolated network,

- conductance criterion for the network with the neutral point earthed by the resistor and the network compensated with AWSCz.

Tables 1-3 present the percentages of overrides and missing overrides of the tested multi-frequency algorithms as a function of the voltage starting threshold and the threshold of the susceptance (conductance) criterion for the algorithm based on the values estimated for the frequency of $50 \mathrm{~Hz}$.

\subsection{Isolated network}

The analysis of the contents of Table 1 allows us to conclude that the application of the developed multi-frequency susceptance criterion used in the algorithm enables a significant reduction in the level of missing diagnoses in comparison with the conventional susceptance criterion, with a low level of redundant classification. One should also pay attention to the relatively low $5 \mathrm{~V}$ inrush voltage level adopted for this criterion and the ability of the new criterion to detect stable earth faults through linear transition resistance, although this criterion was not prepared to detect this type of earth faults.

Figure 4 shows the waveforms of the corresponding signals for the case of an interrupted short-circuit in an isolated network. It should be mentioned that this is a case of an earth fault caused by a relatively high transition resistance $(1 \mathrm{k} \Omega$ ) and intervals between short-circuit arc ignitions of up to $50 \mathrm{~ms}$. As can be seen, although the values of the criterion quantity fluctuate, the sign of the value (signal polarization) is retained and the value is relatively high. This relatively high level of the criterion should be associated with the transients visible in the signals supplying the protection algorithm.

\subsection{Network grounded through a resistor}

The cases of earth faults are presented in Table 2, modeled for MV networks with a point earthed through the resistor did not pose a big challenge with regard to the new criterion and the conventional criterion. This is mainly due to the high level of active current flowing in this network during earth faults in the context of the relative level in entrainment with the compensated network.

Table 1. Efficiency of the earth fault detection algorithm in an isolated network using the $d_{B}$ criterion $d_{B}$ for $N_{f}=60$ and $N_{s r}=60$ $\left(f_{p}=1 \mathrm{kHz}\right)$. Nonlinear and intermittent earthquakes. Comparison with the conventional susceptance algorithm $d_{B}$ for $N_{f}=60$ i $N_{s r}=60\left(f_{p}=1 \mathrm{kHz}\right)$

\begin{tabular}{|c|c|c|c|c|c|c|c|c|c|}
\hline \multirow{3}{*}{$\begin{array}{c}\mathrm{U}_{0 \_ \text {nast }} \\
{[\mathrm{V}]}\end{array}$} & \multicolumn{4}{|c|}{$\begin{array}{c}d_{\mathrm{B}_{0}} \\
N_{\mathrm{f}}=60 \text { i } N_{\mathrm{sr}}=60\left(f_{\mathrm{p}}=1 \mathrm{kHz}\right)\end{array}$} & \multicolumn{5}{|c|}{$\begin{array}{c}\mathrm{B}_{50}> \\
N_{\mathrm{sr}}=100\left(f_{\mathrm{p}}=1 \mathrm{kHz}\right)\end{array}$} \\
\hline & \multicolumn{2}{|c|}{ Nonlinear short circuits } & \multicolumn{2}{|c|}{ Line faults } & \multicolumn{2}{|c|}{ Nonlinear short circuits } & \multicolumn{2}{|c|}{ Nonlinear short circuits } & \multirow[b]{2}{*}{$\begin{array}{l}\mathrm{B}_{0 \_ \text {nast }} \\
{[\mathrm{mS}]}\end{array}$} \\
\hline & $\begin{array}{c}\text { Above } \\
\%\end{array}$ & $\begin{array}{c}\text { Lack } \\
\%\end{array}$ & $\begin{array}{c}\text { Above } \\
\%\end{array}$ & $\begin{array}{c}\text { Lack } \\
\%\end{array}$ & $\begin{array}{c}\text { Above } \\
\%\end{array}$ & $\begin{array}{c}\text { Lack } \\
\%\end{array}$ & $\begin{array}{c}\text { Above. } \\
\%\end{array}$ & $\begin{array}{c}\text { Lack } \\
\%\end{array}$ & \\
\hline 2 & 3.0 & 1.39 & 5.0 & 0 & 0 & 99.72 & 0 & 99.29 & 12.0 \\
\hline 5 & 0.2 & 0 & 0 & 0 & 0 & 59.06 & 0 & 8.60 & 4.8 \\
\hline 10 & 0.37 & 0 & 0 & 0 & 0 & 55.22 & 0 & 0 & 2.4 \\
\hline 15 & 0.46 & 0 & 0 & 0 & 0 & 64.0 & 0 & 0 & 1.6 \\
\hline 30 & 0.67 & 0 & 0 & 0 & 0 & 81.25 & 0 & 0 & 0.8 \\
\hline
\end{tabular}




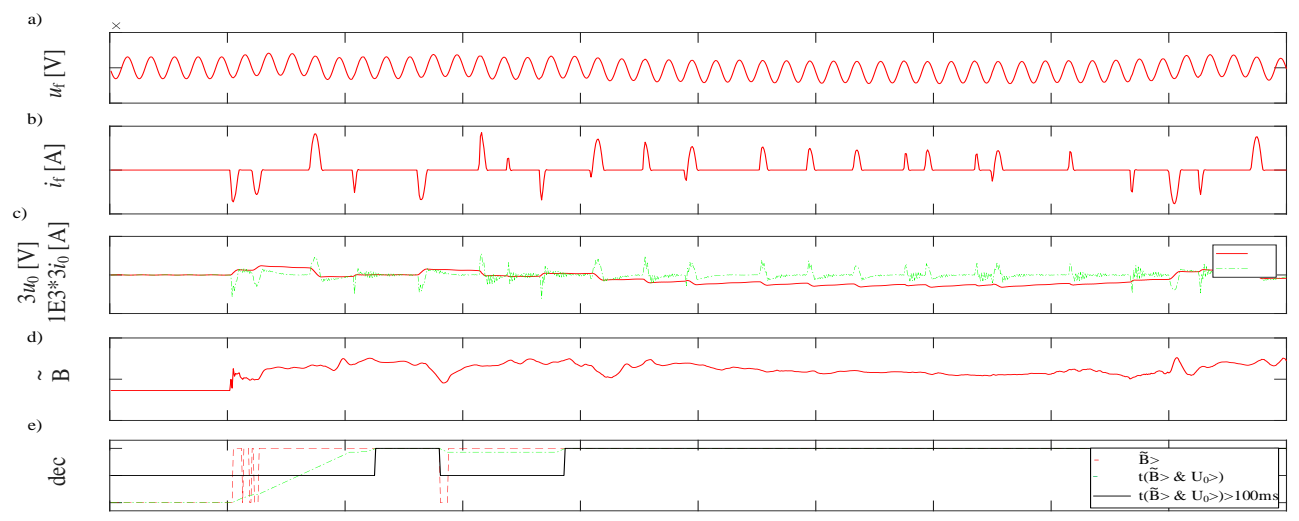

Figure 3. Voltage and current waveforms on the $L 1$ line during an intermittent short-( $\left.M_{3}\right)(a, b)$ at the end of the $L 1$ line; (isolated network, maximum interval between ignitions $50 \mathrm{~ms}, R_{p}=1 \mathrm{k} \Omega$ ); (c) waveforms of the signals supplying the protection with the criterion $B^{\prime}$, (d) values of the criterion quantity $B^{\prime}$, (e) decision-making process.

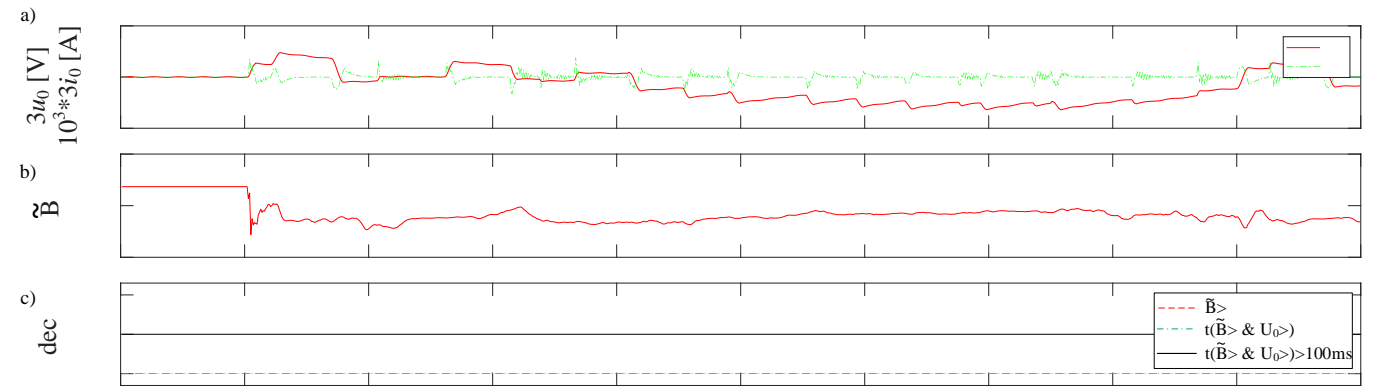

Figure 4. Waveforms of signals supplying the protection in the L5 line (a) with the criterion (isolated network) $B$ ', (b) value of the criterion quantity $B^{\prime}$, (c) decision-making process (the same short-circuit case).

Table 2. Efficiency of the earth fault detection algorithm in a network earthed through a resistor using the criterion $d_{\& \circ}$ for $d_{\varrho \circ} \mathbf{N}_{\mathbf{f}}=\mathbf{8 0} \mathbf{i N}_{\mathrm{sr}}=\mathbf{8 0}\left(\mathbf{f}_{\mathbf{p}}=\mathbf{2} \mathbf{k H z}\right)$. nonlinear and intermittent earthquakes. comparison with the conventional conductance algorithm

\begin{tabular}{|c|c|c|c|c|c|c|c|c|c|}
\hline \multirow{3}{*}{$\begin{array}{l}U_{\text {0nast }} \\
{[\mathrm{V}]}\end{array}$} & \multicolumn{4}{|c|}{$\begin{array}{c}d_{g \circ} \\
N_{\mathrm{f}}=80 \text { i } N_{\mathrm{sr}}=80\left(f_{\mathrm{p}}=2 \mathrm{kHz}\right)\end{array}$} & \multicolumn{5}{|c|}{$\begin{array}{c}\mathrm{G}_{50}> \\
N_{\mathrm{sr}}=120\left(f_{\mathrm{p}}=2 \mathrm{kHz}\right)\end{array}$} \\
\hline & \multicolumn{2}{|c|}{ Nonlinear short circuits } & \multicolumn{2}{|c|}{ Line faults } & \multicolumn{2}{|c|}{ Nonlinear short circuits } & \multicolumn{2}{|c|}{ Nonlinear short circuits } & \multirow[b]{2}{*}{ Nonlinear short circuits } \\
\hline & $\begin{array}{l}\text { Above } \\
\%\end{array}$ & $\begin{array}{c}\text { Lack } \\
\%\end{array}$ & $\begin{array}{c}\text { Above } \\
\%\end{array}$ & $\begin{array}{c}\text { Lack } \\
\%\end{array}$ & $\begin{array}{l}\text { Above } \\
\%\end{array}$ & $\begin{array}{c}\text { Lack } \\
\%\end{array}$ & $\begin{array}{l}\text { Above } \\
\%\end{array}$ & $\begin{array}{l}\text { Lack } \\
\%\end{array}$ & \\
\hline 2 & 1.01 & 0.34 & 1.32 & 0.88 & 0 & 86.15 & 0 & 0 & 12.0 \\
\hline 5 & 0 & 2.33 & 0 & 0 & 0 & 4.19 & 0 & 0 & 4.8 \\
\hline 10 & 0 & 4.95 & 0 & 0 & 0 & 5.94 & 0 & 0 & 2.4 \\
\hline 15 & 0 & 4.0 & 0 & 0 & 0 & 5.33 & 0 & 0 & 1.6 \\
\hline 30 & 0 & 24.0 & 0 & 0 & 0 & 36.0 & 0 & 0 & 0.8 \\
\hline
\end{tabular}

In the figures below, Figure 5 and Figure 6 present the course of the decision process for the case of an earth fault caused by a high transition resistance. The short-circuit model in this case corresponds to the scenario of the phase conductor falling onto a dry substrate, which results in a very low short-circuit current [5]. As it can be seen in Figure 5, the value of the criterion $\mathscr{G} / \mathrm{c}$ in the $\mathrm{L} 3$ healthy line does not change in relation to the pre-short-circuit value, and in the transient state, the change trends are consistent with the sign of the criterion for the steady state. $G^{\circ}$ 


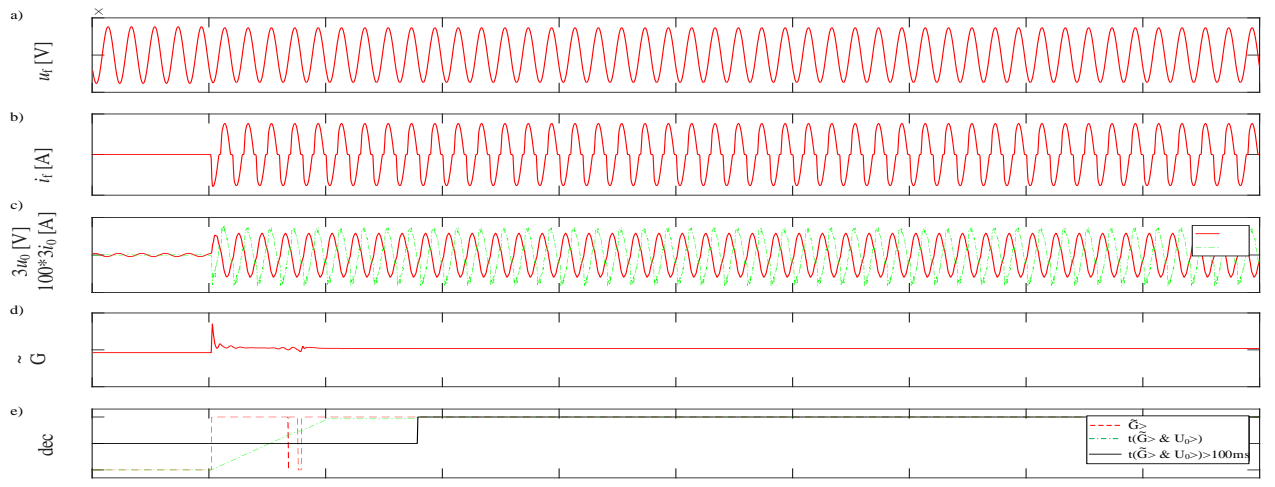

Figure 5. Voltage and current waveforms in the L5 line during short-circuit type (M2) (a, b) at the end of the L5 line (network earthed through a resistor) $q$; ; (c) waveforms of the signals supplying the protection with the criterion $q^{q}$, (d) values of the criterion quantity $o^{\circ}$, , (e) decision-making process.

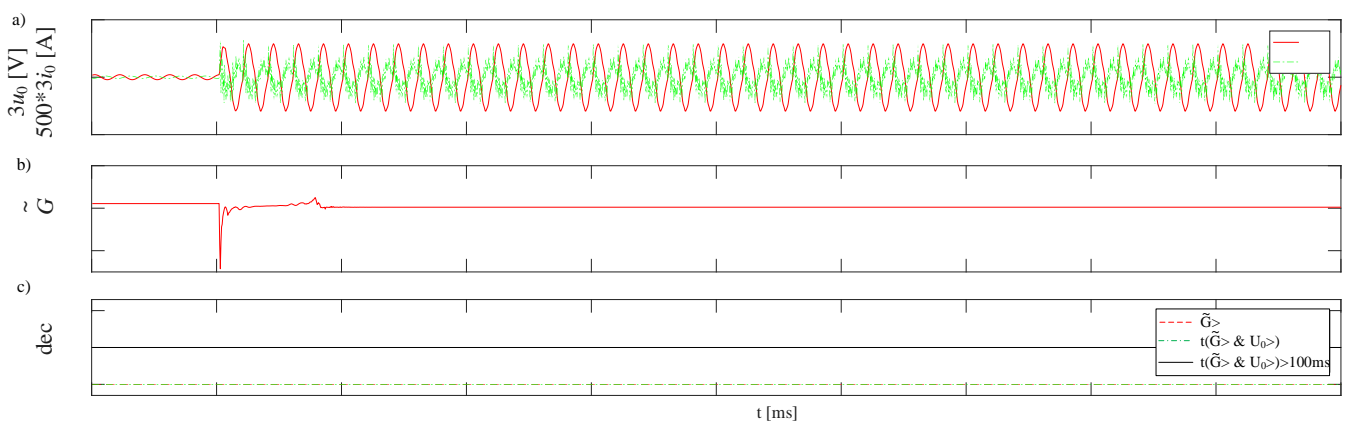

Figure 6. Waveforms of signals supplying the protection in the L3 line (a) with the criterion (network earthed through a resistor) $\&$, (b) value of the criterion value $\mathscr{G}$, (c) decision-making process (short-circuit case).

\subsection{The network is grounded through the Petersen coil from AWSCz}

The time domain analysis also covered the cases of earth faults in the compensated network with automatic forcing of the active component after $500 \mathrm{~ms}$ from the earth fault. Switching on the forcing resistor was determined only by the absolute time of $500 \mathrm{~ms}$ from the beginning of the earth fault $(600 \mathrm{~ms}$ from the beginning of the computer analysis of the states during the earth fault in the MV network) and under the voltage condition 3U0>10 V.

Table 3. Operation of the algorithm of multi-frequency earth fault detection in a compensated network using the $d_{B}$ criterion for dlaN $_{\mathrm{f}}=80 \mathrm{iN}_{\mathrm{sr}}=80\left(\mathrm{f}_{\mathrm{p}}=\mathbf{2 H z}\right)$ for non-linear and interrupted earth faults compared to the conventional conductance criterion

\begin{tabular}{|c|c|c|c|c|c|c|c|c|c|}
\hline \multirow{3}{*}{$\begin{array}{c}\mathrm{U}_{0 \_ \text {nast }} \\
{[\mathrm{V}]}\end{array}$} & \multicolumn{4}{|c|}{$\begin{array}{c}d_{\mathrm{B} 0} \\
N_{\mathrm{f}}=80 \text { i } N_{\mathrm{sr}}=80\left(f_{\mathrm{p}}=2 \mathrm{kHz}\right)\end{array}$} & \multicolumn{5}{|c|}{$\begin{array}{c}\left|G_{50}\right|> \\
N_{\mathrm{sr}}=160\left(f_{\mathrm{p}}=2 \mathrm{kHz}\right)\end{array}$} \\
\hline & \multicolumn{2}{|c|}{ Nonlinear short circuits } & \multicolumn{2}{|c|}{ Line faults } & \multicolumn{2}{|c|}{ Nonlinear short circuits } & \multicolumn{2}{|c|}{ Nonlinear short circuits } & \multirow{2}{*}{$\begin{array}{l}\text { Nonlinear short cir- } \\
\text { cuits }\end{array}$} \\
\hline & $\begin{array}{c}\text { Above } \\
\%\end{array}$ & $\begin{array}{l}\text { Lack } \\
\%\end{array}$ & $\begin{array}{l}\text { Above } \\
\%\end{array}$ & $\begin{array}{l}\text { Lack } \\
\%\end{array}$ & $\begin{array}{l}\text { Above } \\
\%\end{array}$ & $\begin{array}{c}\text { Lack } \\
\%\end{array}$ & $\begin{array}{c}\text { Above } \\
\%\end{array}$ & $\begin{array}{l}\text { Lack } \\
\%\end{array}$ & \\
\hline 2 & 0.22 & 4.66 & 1.27 & 50.28 & 0 & 99.78 & 0 & 100 & 4.0 \\
\hline 5 & 0.14 & 1.09 & 0.32 & 45.86 & 0 & 98.31 & 0 & 94.2 & 4.0 \\
\hline 10 & 0.09 & 1.39 & 0.22 & 31.25 & 0 & 33.7 & 0 & 8.04 & 2.0 \\
\hline 15 & 0.1 & 1.60 & 0 & 20.48 & 0 & 22.0 & 0 & 0 & 1.5 \\
\hline 30 & 0 & 0 & 0 & 16.90 & 0 & 39.51 & 0 & 0 & 1.5 \\
\hline
\end{tabular}

Figure 7 presents the waveforms of protection signals and the decision-making process for the proposed new multi-frequency criterion $B^{\prime}$ developed for the compensated network and the conventional algorithm, using only the quantities determined for the fundamental component. 


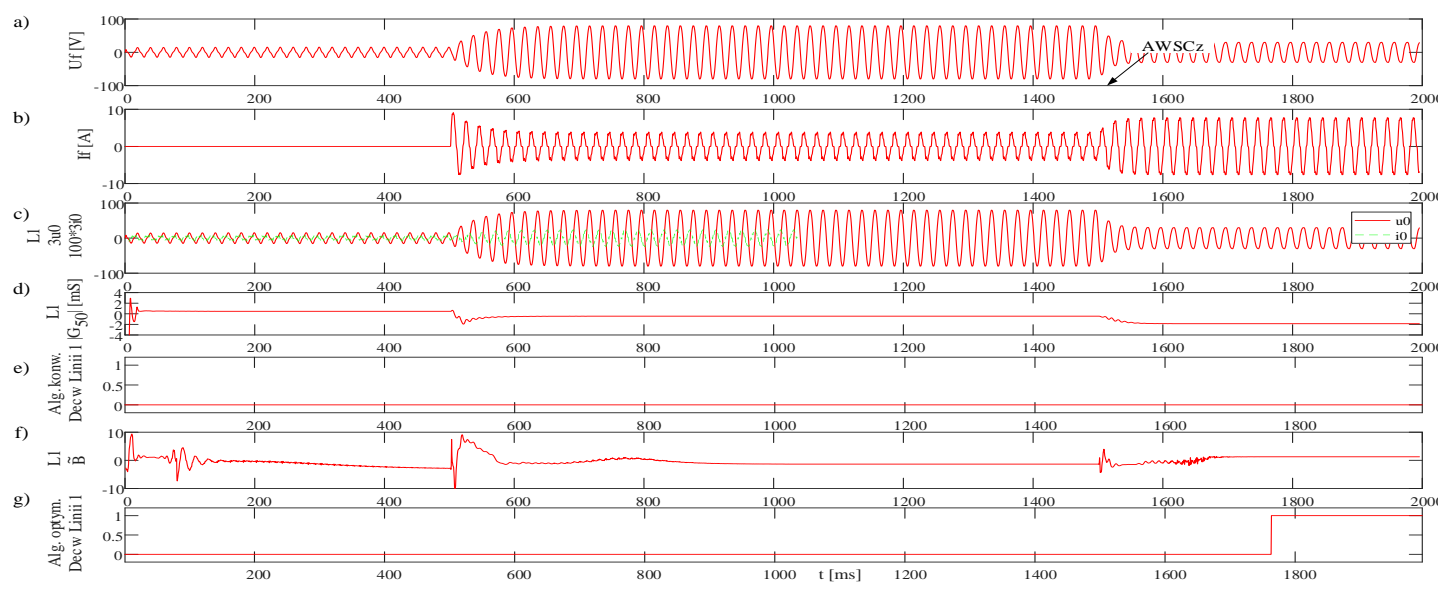

Figure 7. Voltage and current waveforms on the L1 line during M2 short-circuit along the line L1 (a, b); (network compensated with AWSCz; (c) waveforms of signals supplying conventional conductance protection and new with optimized $B^{\prime}$ criterion for $\mathrm{N}_{\mathrm{f}}=80, \mathrm{~N}_{\mathrm{sr}}=200$, (d-f) criteria values and decision-making runs in both protections.

It is a case of earth fault caused by high transition resistance, in which, despite the occurrence of excitation, conventional protection is not able to identify earth fault on the L1 line, even after forcing the active component of the short-circuit current. As can be seen, the same protection algorithm as for the conventional criterion, but powered by an optimized multi-frequency criterion, detects a grounded line after a sufficiently long active component forcing time.

\section{Summary}

The subject of electric power protection automation is all components of the power system that are used for the direct generation, transmission and distribution of electricity. Their common feature is that their essential components function when energized. Since we are talking about electricity, the voltage is accompanied by the flow of electric current. Voltage and current parameters measured in selected places of the power system are the basis for estimating the condition of the system components [4].

The technical system condition can be estimated by means of an active or passive experiment. An active experiment should be understood as deliberate introduction of a test signal (stimulation) to the tested element and observation of the response to this stimulation. These types of tests are used in the power system, e.g. to locate a short circuit, cable damage, etc. However, continuous monitoring of the condition of individual components of the power system must be carried out in the form of a passive experiment. Accordingly, the voltages and currents in the network, which are primarily intended to transmit power, should be regarded as permanently installed test signals from the protection automation point of view. A characteristic feature of these signals is the constancy or very low variation of their frequency (within certain very narrow limits) and the values of the parameters of the signals present in them, i.e. amplitudes, phase angles or their respective relations, characteristic for given types of elements of the system. Therefore, the basic criterion values used in conventional protection relays, designed and built in various technologies, from mechanical to microprocessor, are based on the measurement of voltage and current parameters in the protected objects estimated for a component of the basic power network, i.e. for a component with a network frequency of $50 \mathrm{~Hz}$ or $60 \mathrm{~Hz}$.

All disturbances in the power system operation, including short circuits, lead in the first moments after their occurrence to transient states in the power system. The changes in voltage and current parameters resulting from the disturbance are clearly visible (clearly visible) in the immediate electrical environment of the place of occurrence, and the disturbance symptoms disappear with the distance from this place. Since the values of the basic protection criteria are nowadays estimated by numerical calculations in complex microprocessor systems and they relate to the parameters of protection signals with mains frequency, all physical (electrical and mechanical) transient states of the power system are factors that negatively affect the correctness of the estimation of criteria. An additional factor deteriorating the estimation process is the transient states of the estimators (measurement algorithms such as amplitude, phase angle, impedance, admittance). Of course, these phenomena are in contradiction with the requirement 
of quick decision-making about the condition of the monitored element of the power system. Effective decision-making requires a sufficiently long time of correct measurement of the criterion value.

\section{References}

[1] Wiszniewski, A. (1993). Transformers in electrical engineering T, WNT, Warszawa 1993. ISBN 83-204-1481-4.

[2] Altonen, J., Wahlroos, A., Vahakuopus, S. (2017). Application of multi-frequency admittance based fault passage indication in practical compensated medium-voltage network, 24th International Conference \& Exhibition on Electricy Distribution (CIRED), Glasgow 12-15 June 2017, pp. 947-951.

[3] Hoppel, W. (2017). Medium voltage networks. Protection automatics and protection against electric shocks, Wydawnictwo Naukowe PWN SA, Warszawa 2017. ISBN: 978-83-01-19346-1.

[4] Kang Zhongjian, Li Dandan, Zhang Chao, Liu Xiaolin. (2010). Research on the Fault Characteristic in Non-Effectively Grounding Distribution Network with a Single-phase-to-earth Fault Based on Hilbert-Huang Transform, 2010 International Conference on Intelligent System Design and Engineering Application, 13-14 Oct. 2010, Changsha, Hunan, China, pp. 276-279.

[5] Kremens, Z., Sobierajski, M. (1996). Power systems analysis, WNT, Warszawa 1996.

[6] Synal, B. (1991). Power automation, Laboratory exercises, Part II, Protection and control automation systems, Oficyna Wydawnicza Politechniki Wrocławskiej, Wrocław 1991.

[7] Tao Cui, Xinzhou Dong, Zhiqian Bo, Juszczyk A. (2001). Hilbert-Transform-Based Transient/Intermittent Earth Fault Detection in Noneffectively Grounded Distribution Systems, IEEE Trans. On Power Delivery, Vol. 26, No. 1, Jan. 2001.

[8] Altonen, J., Wahlroos, A. (2014). Application of novel multi-frequency neutral admittance method into earth-fault protection in compensated MV-networks; 12th IET International Conference on Developments in Power System Protection (DPSP 2014), April 2014.

[9] Miroslaw Lukowicz, Krzysztof Solak, Bernard Wiecha. (2020). Optimized bandpass admittance criteria for earth fault protection of MV distribution networks. International Journal of Electrical Power and Energy Systems. Volume 119, July 2020105855. 